\title{
Sentimentos de familiares sobre o futuro de um ser esquizofrênico: perspectivas para o cuidado de enfermagem
}

\author{
Family feelings about the future of a schizophrenic being: \\ perspectives for nursing care \\ Sentimientos de familiares acerca del futuro de un ser esquizofrénico: \\ perspectivas para el cuidado de enfermería
}

\section{Catarina Aparecida Sales', Patrícia Aparecida Pedro Schülhi', Elionésia Marta dos Santos', Nayara Mizumo Tironi", Eloana Ferreira D'Artibale", Maria Aparecida Salci" \\ ' Universidade Estadual de Maringá (UEM). Departamento de Enfermagem. Mestrado em Enfermagem. Maringá-PR, Brasil. \\ ' Universidade Estadual de Maringá (UEM). Departamento de Enfermagem. Curso de Graduação em Enfermagem. Maringá-PR, Brasil.}

Submissão: $23 / 11 / 2009$

Aprovação: 29/05/2010

\section{RESUMO}

Pesquisa qualitativa, com abordagem fenomenológica, em que se objetivou compreender as expectativas dos familiares em relação ao futuro de seu ente portador de esquizofrenia. Foram realizadas entrevistas com seis familiares de pacientes esquizofrênicos do Município de Maringá - PR, nos meses de maio e junho de 2008. A análise suscitou uma temática central, A temporalidade de estar-com um ente esquizofrênico e, desta, três subtemas: Preocupando-se com o abandono, Experienciando a desesperança e a incerteza e Vivenciando a esperança de cura. O estudo despertou-nos, no universo do cuidado, para a importância do tempo, tantas vezes negligenciado por nós, profissionais da saúde, por não apreendermos o sentido dessa temporalidade na vivência dos seres de quem cuidamos.

Descritores: Enfermagem; Cuidado de enfermagem; Família, Relações interpessoais.

\section{ABSTRACT}

This is a qualitative research, with phenomenological approach, that aimed to understand the family expectations regarding the future of a family member suffering of schizophrenia. For data collection, interviews were carried out with six relatives of schizophrenic patients of the municipal district of Maringá-PR, during the months of May and June, 2008. The analysis brought up a central theme, The temporality of being with a schizophrenic individual, and, from that, three sub-themes: Worrying about the abandonment, Experiencing despair and uncertainty and Living the hope for cure. The study called our attention to the importance of time in the universe of nursing care, so often neglected by us, health professionals, for we do not understand the meaning of temporality in the living experience of the beings we care for.

Key words: Nursing; Nursing care; Family, Interpersonal relationship.

\section{RESUMEN}

Este estudio tuvo como objetivo comprender las expectativas de los familiares con relación al futuro de su ente portador de esquizofrenia. Se trata de una investigación cualitativa que utilizó el abordaje fenomenológico. Fueron realizadas entrevistas con seis familiares de pacientes esquizofrénicos del Municipio de Maringá - PR, en los meses de mayo y junio de 2008 . El análisis suscitó una temática central, La temporalidad de estar con un ente esquizofrénico, y de esta, tres subtemas: Preocupándose con el abandono, Experimentando la desesperanza y la incertidumbre y Vivenciando la esperanza de cura. El estudio nos despertó para la importancia del tiempo en el universo del cuidado, tantas veces descuidado por nosotros, profesionales de la salud, por no aprehender el sentido de esa temporalidad en la vivencia de los seres de quienes cuidamos.

Palabras clave: Enfermería; Cuidado de enfermería; Familia; Relaciones interpersonales. 


\section{INTRODUÇÃO}

A esquizofrenia é uma doença heterogênea no que se refere a sua etiologia, sintomatologia, gravidade, duração, curso e resposta ao tratamento ${ }^{(1)}$. Seus sintomas mais comuns, apesar das diferenças dos padrões de personalidade prévia, caracterizam-se principalmente pela mania de perseguição e por alucinações visuais e auditivas ${ }^{(2)}$, o que a caracteriza como um distúrbio grave e persistente que resulta em comportamento psicótico, deterioração do pensamento concreto e dificuldades no processamento das informações, nos relacionamentos interpessoais e na resolução de problemas ${ }^{(3)}$.

Um dos fatores que tornam a esquizofrenia uma doença de alto impacto sobre o indivíduo é seu aparecimento precoce, sendo as manifestações clínicas mais frequentes na adolescência e início da vida adulta ${ }^{(1)}$. Ademais, na grande maioria dos indivíduos, após a primeira vez a crise se apresenta pelo resto da vida, o que demanda um inegável envolvimento familiar em todo o processo de cuidado ${ }^{(3)}$. Assim, a principal rede de suporte natural do indivíduo portador de esquizofrenia é a família, sendo comum que muitos doentes vivam com pelo menos um familiar ${ }^{(4)}$, o que leva a que as sobrecargas geradas pelo adoecimento se concentrem nos familiares, especialmente no que se refere ao comportamento do paciente.

Um estudo realizado com familiares de pacientes esquizofrênicos ${ }^{(5)}$ identificou que o cuidador imediato sofre as sobrecargas de doença física e emocional, em decorrência dos desgastes provocados pelo comportamento dos seus doentes e de terem que executar o cuidado e vigiá-los diuturnamente, o que torna extremamente difícil a convivência domiciliar, sendo até mesmo mais prejudicial do que a sobrecarga financeira, que também está presente na realidade de várias famílias.

Ao descobrir a esquizofrenia em seu lar, os familiares adentram em uma nova realidade que desperta uma série de sentimentos. O impacto gerado na família em razão do adoecimento suscita situações de estresse, cansaço e desesperança, pois ela muitas vezes não compreende o que está realmente ocorrendo com o seu familiar(6).

Conviver com um ente portador de esquizofrenia pode ser uma experiência angustiante, na medida em que emergem sentimentos de incerteza quanto ao presente e ao futuro de seu familiar, que envolvem as suas próprias perspectivas de vida. Nesses momentos, muitos questionamentos são suscitados no seio familiar: "Algum dia ele voltará a ser como antes? Existe chance de cura? Como ele se comportará diante de uma nova situação? E se ele piorar?"

Acreditamos que as expectativas dos familiares em relação ao futuro desse ente possam refletir a sua experiência em relação ao cuidado para com esse indivíduo, bem como sua compreensão sobre a doença, uma vez que as experiências emocionais positivas dos familiares estão intimamente relacionadas com a sua expectativa em relação à pessoa doente ${ }^{(6)}$.

Assim, objetivamos com este estudo compreender as expectativas dos familiares em relação ao futuro de seu ente portador de esquizofrenia, considerando que na atualidade constitui-se um desafio compreender as famílias em suas especificidades, principalmente na vivência de uma doença mental, no que tange ao cuidar destes seres.

\section{O CAMINHO METODOLÓGICO}

Para contemplar a proposta do estudo, optamos por uma pesquisa qualitativa numa abordagem fenomenológica, pois, aplicado ao problema do ser, o método fenomenológico coloca como ponto de partida a reflexão do ser que se dá a conhecer imediatamente, ou seja, o próprio homem, colocando-o dentro de uma dimensão ontológica.

Assim, a investigação fenomenológica não vai partir de um problema, mas de uma interrogação. Quando o pesquisador interroga, ele terá uma trajetória e estará caminhando em direção ao fenômeno, naquilo que se manifesta por si, por meio do sujeito que experiencia a situação. Destarte, para saber algo que nos leve à compreensão das expectativas dos familiares devemos interrogá-los em sua mundaneidade do mundo, ou seja, em seu próprio mundo humano ${ }^{(7)}$.

Neste caminhar, voltamo-nos à família, para tentar desvelar suas concepções em relação ao porvir do seu ente portador de esquizofrenia. A aproximação com os familiares ocorreu por meio do projeto de pesquisa intitulado "Saúde mental na atenção básica: perspectivas e intervenção", do Departamento de Enfermagem da Universidade Estadual de Maringá (UEM), desenvolvido na área de abrangência da unidade básica de saúde Mandacaru, do município de Maringá-PR. Neste perímetro identificamos seis famílias que tinham um membro portador de esquizofrenia, as quais fizeram parte deste estudo.

O primeiro contato com as famílias se deu via telefone, sendo solicitado consentimento para visitarmos seu domicílio. Com permissão dos cuidadores, iniciamos a entrevista, a qual foi realizada no domicílio de cada família em maio e junho de 2008, sendo respondentes uma cunhada, quatro irmãs e duas mães.

Para as entrevistas, utilizamos gravador e a observação. Os familiares foram inquiridos com a seguinte questão norteadora: "Fale-nos de suas expectativas em relação ao futuro de seu familiar esquizofrênico".

Para captar a plenitude expressa pelos sujeitos em suas linguagens, optamos pela análise individual de cada discurso. Assim, a priori, realizamos leituras atentas de cada depoimento, separando os trechos ou unidades de sentidos (US) que, para nós, se mostraram como estruturas fundamentais da existência. A posteriori, passamos a analisar as unidades de sentidos de cada depoimento, realizando seleção fenomenológica da linguagem de cada sujeito, pois uma unidade de sentidos, em geral, compreende sentimentos que são revelados pelos depoentes e contemplam a interrogação ontológica ${ }^{(8)}$.

Por se tratar de uma pesquisa que envolve seres humanos, observamos os aspectos éticos disciplinados pela Resolução no 196/1996 do CNS-MS. A proposta de intenção para realização do estudo foi apreciada e aprovada pelo Comitê Permanente de Ética em Pesquisa com Seres Humanos da Universidade Estadual de Maringá, Parecer $n^{\circ}$ 110/2007(9). A solicitação de participação no estudo se fez acompanhar de 
duas vias do "Termo de Consentimento Livre e Esclarecido". Nesta solicitação, notificamos as famílias sobre as finalidades da pesquisa, o tipo de participação desejado e o tempo provável de duração da entrevista.

Asseguramos também aos partícipes a desvinculação entre a pesquisa e o atendimento prestado pelos serviços de saúde, o livre consentimento e a liberdade de desistir do estudo se em qualquer momento o viessem a desejá-lo, e ainda sigilo quanto às informações prestadas e anonimato sempre que os resultados viessem a ser divulgados, e neste estudo, para manter o anonimato dos depoentes, referenciamo-los com nomes de flores.

\section{RESULTADOS E DISCUSSÃO}

Pela análise dos discursos dos depoentes constatamos que os seus sentimentos se entrelaçam em constituições ontológicas temporais. Assim, vislumbramos uma temática central, A temporalidade de estar-com um ente esquizofrênico, da qual se destacaram três subtemas - Preocupando-se com o abandono, Experienciando a desesperança e a incerteza, e Vivenciando a esperança de cura - os quais foram interpretados à luz de algumas ideias da analítica heideggeriana, articuladas com o pensar de pesquisadoras da enfermagem que vivenciam a temática em seus cotidianos.

\section{A temporalidade de estar-com um ente esquizofrênico}

Em o Ser-aí e temporalidade encontramos a interpretação do homem autenticamente existente, isto é, o ser-no-mundo em sua temporalidade.

Na decisão antecipativa, ou seja, na forma originária e autêntica do cuidar, o homem desvela todo o seu poder-ser, sendo que esse poder-ser manifesta-se em uma constituição temporal. É uma temporalidade primitiva que se temporaliza conforme três ek-stases ou etapas; o porvir (futuro), o vigor de ter sido (passado) e a atualidade (presente). "A temporalidade desentranha-se como o sentido da cura propriamente dito"(7).

Nesta perspectiva, o futuro não representa um conjunto de eventualidades que ainda não ocorreram, mas sim, o movimento pelo qual o Ser-aí, ao preceder-se a si mesmo, toma consciência de estar à mercê do tempo, pois tudo ao seu redor aloja-se no futuro. Apreende-se, assim, tratar-se de um ente abandonado-no-mundo e vivenciando as facticidades de sua existência. O movimento pelo qual ele faz o retorno ao seu estar-lançado constitui o passado ${ }^{(7)}$.

A última $\mathbf{e}$-stase da temporalidade é o presente. Não representa o momento atual da temporalidade coloquial, mas como um existenciário, indica o movimento pelo qual o Ser-aí, projetando-se para o seu poder-ser mais próprio e assumindo seu existir-no-mundo, descobre um mundo que é seu, isto é, sua própria situação. A presentificação do presente autêntico pelo homem denomina-se is-stante (Augenblick), o momento em que ele se torna livre para vivenciar seu mundo e descobrir suas possibilidades de enfrentar a situação ${ }^{(7)}$.

\section{Preocupando-se com o abandono}

Na elucidação heideggeriana o temor caracteriza-se como uma disposição imprópria, pois encontra seu ensejo nos entes que vêm ao seu encontro descortinando um "malum futurum". O significado existencial e temporal do temor constitui-se de um esquecimento de si mesmo. O temor proporciona o afastamento do Ser-aí do seu poder-ser mais próprio e, nesse esquecimento, ele não se reconhece mais em seu mundo circundante e não visualiza as várias possibilidades ao seu redor, pois no temor o homem perturba-se diante do mundo, tornando-se aflito e conturbado ${ }^{(7)}$.

Um estudo com mães de pacientes psiquiátricos aponta o descompasso temporal como categoria principal da pesquisa, por retratar o desânimo e a desesperança ante as possibilidades de reabilitação dessa doença, uma vez que as "coisas mundanas" parecem paralisar-se no tempo quando se trata de uma perspectiva de futuro para o doente mental, e nesse ínterim o ambiente familiar fica mais suscetível e vulnerável e capaz de gerar constantes conflitos $^{(4)}$.

Nesse sentido, na fala de Camélia, distinguimos que ela desvela ter consciência das condições existenciais de seu familiar causadas pela doença e exprime seu temor ante a possibilidade que no porvir ele ser abandonado pelos seus entes próximos.

Ela tem os três filhos homens, né? Poxa! Deus o livre um dia ela ficá... Ela tem os três filhos homens e vai ter três noras também que eu não sei se vão querer cuidar dela. Por que hoje em dia é tão difícil você achar uma nora que vai querer cuidar da sogra? Nossa, vai ser muito difícil. Eu falo muito com eles, eu converso com eles. (Camélia)

O ser humano, como Ser-lançado-no-mundo, vive uma situação ambígua, isto é, sente-se abandonado e ao mesmo tempo tem o poder de escolher seu próprio destino, isto é, viver de uma forma autêntica ou inautêntica perante as vicissitudes da vida. Na existência inautêntica, o Ser-no-mundo vive uma abertura que não lhe pertence como algo de que possa dispor, e nessas condições ele fecha-se em si mesmo, alienando-se totalmente de sua principal missão, que seria tornar-se ele mesmo, escondendo-se em sua dimensão mais profunda e não vislumbrando as possibilidades de superar sua própria angústia ${ }^{(7)}$.

Eu não tenho a natureza dela... Se eu fosse viúva eu casava de imediato. Ela pensa que está velha, feia que não pode arrumar ninguém. Ela não pensa nisso. Se ela colocar isso na cabeça ela vai ficar sozinha o resto da vida. Sozinha, por que os filhos cada um é cada um. Eu falo muito para ela se soltar, esquecer o que já foi. A vida dela não parou por causa do problema dela. Ela tem que arrumar uma pessoa que ame ela, que zele por ela, para começar a vida dela, não parar. (Azaléia)

Nesse pensar, notamos na linguagem de Azaleia a preocupação com a probabilidade de uma vida solitária para seu ente querido, e ao expressar "eu falo muito para ela se soltar, esquecer o que já foi", transmite a necessidade de ela não se prender ao seu vigor de ter sido (passado), isto é, não permanecer enredada ao tempo em que podia sonhar, ser feliz, viver 
livremente, e, principalmente, transcender esse ik-stante (presente) e buscar razões para encontrar sentido para sua existência mesmo sendo portador de esquizofrenia, manifestando assim seu poder de transcendência sobre si mesmo e sobre o mundo. Acerca desta questão destacamos que, "quando o ser-ai descobre o mundo em seu próprio modo e o aproxima, quando desvela para si mesmo seu próprio autêntico ser, essa descoberta do 'mundo' e esse desvelamento do 'ser ai' são consumados como um libertar-se das ocultações e das eclipses, como um rompimento dos disfarces com os quais o 'ser ai' mesmo obstrui seu próprio modo, chegando assim a ser propriamente ele mesmo, ou seja, si mesmo"(10).

$\mathrm{Na}$ analítica heideggeriana, o ser humano é um ser-no-mundo que existe sempre em relação com algo ou alguém, e neste estado compreende as suas experiências e estabelece significado próprio aos objetos e seres em seu mundo e dá sentido à sua existência. Neste prisma, os utensílios ou objetos não são uma realidade simplesmente subsistente, mas está fundamentalmente disponível para um uso determinado. O utensílio é essencialmente alguma coisa de que o homem dispõe para viver no mundo ${ }^{(7)}$.

Assim, na unidade de sentidos a seguir o familiar enfatizou seu desassossego com a estabilidade econômica e social de seu familiar esquizofrênico, lamentando não poder assegurar-lhe um futuro estável, pois, em seu pensar, uma renda fixa seria um utensílio importante para o seu porvir, uma vez que ele tem dificuldade em modificar seus hábitos diários, como também em aceitar a doença.

Se eu pudesse mesmo queria aposentar ela, por que com a aposentadoria ela se sustentava, né? Se ela se equilibra para se sustentar, por que do jeito que ela come toda hora, ela não tem hora certa para comer [...] Se ela tomasse os remédios direitinho ela melhorava. Acredito que ela meIhorava. (Violeta)

Ao se descobrir como ser-no-mundo, o homem sempre se descobre como ser-com (Mit Sein), sendo o outro (Mit Dasein) também um ser-no-mundo, ou seja, um ser para os outros, um companheiro. E é nesse ser-com-o-outro que o homem visualiza a possibilidade de situar-se com alguém, não apenas na forma de objeto de cuidado, mas de uma forma envolvente e significante ${ }^{(11)}$.

Não obstante, o homem, em seu existir-no-mundo, geralmente não questiona sua existência. Como ele subsiste num estado de queda, em que a afetividade revela-se como mera curiosidade, sua compreensão é enleada pelas ambiguidades e seu discurso é limitado a palavras vazias, ou seja, o ser-no-mundo vive uma existência inautêntica; mas quando alguma vicissitude vem ao seu encontro e, entendendo sua condição de ser abandonado no mundo, o homem transcende essa inautenticidade, existindo de uma forma autêntica. Nesses momentos desvela-se como um autêntico Ser de cura. Nesta perspectiva pontuamos a seguinte fala;

O tratamento enquanto eu viver e tiver forças, e depois uma casa-lar, bem paga pela família, onde elas vão ter um tratamento quase igual o que tinha comigo, não digo totalmente, porque o futuro delas eu não vou deixar assim, como a minha mãe deixou [...] Para mim o futuro delas é esse, uma casa-lar, todas as duas, que eu sei que lá elas pagam, são bem tratadas. Se eu morrer hoje e elas ficarem assim o que será delas. Então eu já estou arrumando tudo, já paguei os advogados, para deixar elas em uma casa lar mesmo [...]. Então o futuro quem tem que fazer é quem está cuidando. (Jasmim)

$\mathrm{Na}$ linguagem de Jasmim notamos sua preocupação em não apenas estar-com seu familiar esquizofrênico nesse is-stante de sua vida, mas também em assegurar-lhe abrigo seguro para seu porvir. Observamos ainda que esse desejo suscita-Ihe sentimentos que o fortalecem para enfrentar sua fatalidade existencial, enfatizando no final da unidade de sentidos a importância de o cuidador informal implementar medidas que garantam um futuro com qualidade de vida para seu familiar esquizofrênico. O envolvimento afetivo característico dos liames familiares de alguma forma orienta as tentativas de entendimento e as buscas de solução para muitas questões pertinentes ao convívio com um familiar doente ${ }^{(12)}$.

\section{Experienciando a desesperança e incerteza}

$\mathrm{Na}$ meditação heideggeriana, a decadência constitui um aspecto do cotidiano que revela a existência inautêntica do ser-no-mundo, pois significa o desvio de cada indivíduo de seu projeto essencial em favor das preocupações cotidianas, que o distraem e perturbam, confundindo-o com a massa coletiva e ausentando-se de estar-com-o-outro. Não obstante, para o pensador, nem todo retirar-se é necessariamente uma fuga, ao contrário, "o desvio da decadência funda-se na angústia que, por sua vez, torna possível o medo"(7).

Nesta perspectiva, notamos na interlocução que esse sentimento de medo advém da desesperança causada pela angústia enredada nesse is-stante de sua vida, a qual resulta da impossibilidade ou possibilidade de seu familiar esquizofrênico voltar a ter uma vida normal. "A doença, nessas condições, propicia o estar-com o vazio, no nada, no silêncio, como forma de preocupação e angústia, que se constitui como parte integrante da existência" ${ }^{\prime 13)}$.

Para o futuro não penso nada diferente do que é agora, nada diferente. Não vejo mudança, a não ser a possibilidade de uma cirurgia ou de outro medicamento ou tratamento que altere tudo isso. Do contrário, não vejo nada, nada, nada de melhora. (Orquídea)

É comum o encontro com familiares pessimistas quanto à possibilidade de melhora do familiar doente mental, pois são tantos os fracassos, recaídas, abandonos de tratamento, que com o passar do tempo essas complicações e conflitos trazem a desmotivação, resistência e temores em relação a qualquer proposta de mudança ${ }^{(14)}$. Assim o processo de vivenciar a doença mental no lar tem também a característica de despertar nos membros familiares a vivência de um processo compulsório de reorganização de suas dinâmicas ${ }^{(4)}$, sobrando apenas o 
encontro de novas estratégias para um melhor convívio diário com o paciente psiquiátrico, como refere Gérbera:

Com o conhecimento atual não tenho muita esperança (o futuro), vai continuar o que está acontecendo agora e que sempre aconteceu. Hoje eu acho que não é ele que está melhor, nós é que aprendemos a conviver e a aceitar aquela situação e saber lidar com ela, porque se você não souber lidar sua vida se torna um inferno, desestrutura muito, muito mesmo. (Gérbera)

Entretanto, na analítica heideggeriana a transcendência está intimamente ligada à facticidade, isto é, não há transcendência sem facticidade e o ser humano somente supera a si próprio quando algum acontecimento não planejado nem esperado vem ao seu encontro, avivando-lhe necessidades de orientações e conforto. Nesse pensar, acreditamos ser importante que o enfermeiro desperte para o fato de que talvez o mais importante não seja a doença, mas sim, seus significados e o que estes podem provocar no seio familiar ${ }^{(15)}$. Para isto se faz necessário adotar medidas destinadas a encontrar caminhos que levem à almejada reforma nas ações e nos serviços de saúde mental / psiquiatria ${ }^{(16)}$. Ao interagir de uma forma autêntica com o doente mental e sua família, o enfermeiro "favorece a busca e o encontro do sentido da vida e do sofrimento dos seus pacientes e ao realizar tal tarefa ele próprio encontra o sentido de sua vida, por autotranscender-se e insistentemente maximizar sua função terapêutica por ir ao encontro da parte inatingível do ser, o seu espírito"(17).

Uma vez que a desorganização no seio familiar é vivenciada em decorrência da doença mental, esta traz consequências sociais diversas e irreparáveis para algumas famílias, colocando-as em uma posição de não conciliação com os ciclos naturais de passado, presente e futuro ${ }^{(4)}$. Nesses momentos cabe à família promover o contato entre o doente e os serviços de saúde existentes e lidar com as situações de crise, decidindo quando é possível o manejo em casa e quando buscar ajuda emergencial e, junto com o profissional de saúde envolvido, fornecer informações que contribuam para uma convivência menos dolorosa ${ }^{(12)}$.

\section{Vivenciando a esperança de cura}

$\mathrm{Na}$ analítica heideggeriana a angústia é uma possibilidade ontológica que revela o horizonte ôntico do homem como ente. Não obstante, esse mostrar-se do Ser-aí advém de sua abertura ao mundo com disposição e compreensão, pois a angústia surge do próprio homem, à medida que este se percebe um ser-lançado-para-a-morte. O filósofo observa ainda que a angústia não desentranha um ser aflito e conturbado com o temor, ao contrário, libera o Ser-aí de suas possibilidades nulas, tornando-o livre para assumir as possibilidades concretas de seu existir ${ }^{(7)}$.

Assim, é na angústia que se revela o abandono do homem a si mesmo, ao encontrar face a face com sua terrível liberdade de ser ou não ser, de permanecer na inautenticidade ou lutar pela posse de si mesmo, pois, o ser humano é antes de tudo um ser-no-mundo temporal, e, sem a perspectiva de um futuro melhor, ele viveria existencialmente aniquilado.
Nesse pensar, notamos no discurso de Jasmim que, apesar dos sofrimentos que foram impostos ela tem esperança de que surja alguma solução para o problema de seu ente familiar, uma vez que da esperança - ao contrário da desesperança nasce a possibilidade de uma vida melhor no porvir.

Se ela melhora mesmo, que fica bem, que ela pode voltar para casa dela. Cuidar dos filhos dela, os filhos dela vão ter filhos, ela vai ter netos. Eu sinto assim que Deus ainda vai abençoar muito que ela vai voltar para casa dela, que ela ainda vai poder cuidar da casa dela. Ou às vezes vir morar para cá, não sei. Por que ela ainda esta nova, né? Ainda tem muita vida pela frente. (Jasmim)

Todavia, no discurso existencial heideggeriano, se por um lado o homem relaciona o temor a um "malum futurum", por outro ele visualiza na esperança o desenvolver-se de um "bonum futurum", pois a esperança traz ao Ser-aí a força necessária para emergir de sua angústia e vislumbrar novas possibilidades. "Aquele que tem esperança se carrega, por assim dizer, a si mesmo para dentro da esperança, contrapondo-se ao que é esperado"(7).

O caminho da esperança foi expresso pelos depoentes através da fé, pois nestas falas observamos que os sujeitos trazem em si a crença de que alguém está olhando por eles, o que caracteriza a esperança como uma possibilidade própria de cada um. As manifestações a seguir ilustram esta interpretação.

Estou esperando em Deus, porque vou esperar de quem? A gente é pobre [...] Eu sinto tristeza, dó por que ele sofre muito com essa coisa, porque ele queria ajudar o pai dele, ter o trabalho dele. Isso é normal, porque eu tenho meus netos são novos ainda mais já trabalham, já dirigem, tem seu carro. Todos têm seu trabalho, todos têm seu dever, e ele parou. Então, dói lá dentro e eu não tenho o que fazer, não sei o que fazer mais, mando ele em qualquer médico. (Lírio)

A fé é uma fonte de apoio no enfrentamento de doenças, bem como de força para suportar os desafios impostos por elas, ou até confortar-se diante da impossibilidade de cura. A fé dá esperança e conforta a alma. O ser humano que acredita vai além da compreensão das impossibilidades, buscando a cada dia um sentido para as suas vicissitudes cotidianas ${ }^{(18)}$.

Nesse prisma, percebemos que Lírio exprime em sua fala sentimentos de tristeza e impotência ante uma doença, que não tem perspectivas de cura, negando ao doente a possibilidade de voltar a sonhar, de conquistar com seu esforço uma vida digna; mas apesar de todas as vicissitudes, ela busca na fé alento para sua agonia.

Às vezes você consegue que ele comece a sentir uma esperança, então, na realidade, é exatamente isso que controla o meu irmão, é a esperança de alguma coisa. É isso o que eu sempre falo para o neurologista dele: 'se ele perder a esperança, acabou o controle que ele tem, acabou a forma da gente conseguir controlar ele e as crises dele'. (Gérbera) 
No pensar de Gérbera, somente a crença em algo maior pode proporcionar a paz e tranquilidade que seu ente precisa para dar continuidade a sua existência. A família que cuida de um doente mental apega-se às crenças religiosas como consolo para suas angústias e como sustentação de suas forças para prosseguir cuidando do portador de transtorno mental ${ }^{(19)}$.

Assim, no final da unidade, quando Gérbera expressa; "se ele perder a esperança, acabou o controle que ele tem, acabou a forma da gente conseguir controlar ele e as crises dele", vislumbramos sua luta para manter acessa a chama da esperança no viver de seu irmão, pois sente que a ausência deste sentimento o fará sucumbir em si mesmo, vivendo em um mundo sem mundo, onde todas as possibilidades tornam-se perdidas no tempo. Neste relato entendemos também que "o sofrimento, portanto, evoca significados desde força e fraqueza, medo e coragem, despertando emoções positivas ou negativas na pessoa em sofrimento"(20).

Entendemos também que, por ser um Ser temporal e histórico, cada ser humano vive sua temporalidade e sua historicidade a cada momento. Desta forma, cada indivíduo vê a doença e o sofrimento e Ihe atribui um sentido em conformidade com a etapa em que se encontre no processo de desenvolvimento vital. Não obstante, esta percepção depende de sua história de vida, de suas vivências, aprendizagens e desejos. Em qualquer fase do desenvolvimento humano de uma pessoa esquizofrênica a idéia da doença está presente e tem uma representação característica, trazendo um entrelaçamento de todos os aspectos vivenciados em seu cotidiano.

\section{CONSIDERAÇÕES}

Este estudo despertou-nos para a importância do tempo no universo do cuidado, esse tempo, tantas vezes negligenciado por nós, profissionais da saúde, por não apreendermos o sentido dessa temporalidade nas vivências dos seres de quem cuidamos. Cuidamos em um tempo cronológico, no aqui-e-agora, assim não vislumbramos o tempo como um fio condutor na humanização plena do cuidado.

Não obstante, pelos relatos dos sujeitos que participaram da pesquisa foi possível apreender o tempo como algo que os torna seres angustiados, pois ao transcender o presente vivido na condição de cuidador de um familiar com transtorno mental em casa, eles demonstram trazer em seu âmago preocupações relativas ao porvir de seu ente. Assim, compreendemos que as lembranças do passado e o sofrimento do presente suscitam neles a incerteza quanto ao futuro.

Depreendemos que cuidamos na ausência deste tempo, pois atribuímos a este a razão pela qual não compartilhamos plenamente as vivências com os familiares que cuidam de pessoas esquizofrênicas; mas no caminhar deste estudo refletimos sobre o tempo, cuja falta frequentemente é a desculpa do profissional de saúde para esconder-se de seu próprio poder-ser, ou seja, um Ser de e para o cuidado: o tempo para conversar, para tocar e principalmente, ouvir suas manifestações cotidianas decorrentes de sua facticidade.

Sobretudo, este estudo despertou-nos para o fato de que o mesmo tempo que o outro talvez necessite é o tempo de que o profissional precisa para libertar-se de suas angústias ante a dominação de um sistema que absorve o Ser enfermeiro com exigências burocráticas, como relatórios, que o afastam da execução humanística da assistência.

Destarte, torna-se necessária a utilização de um processo de cuidar em que essas famílias não sejam apenas seres esquecidos em suas facticidades, mas sejam acompanhados nesse processo, estabeleçam metas e troquem experiências com a equipe, para assim viver de forma menos dolorosa com a esquizofrenia em seu lar.

Devemos ressaltar ainda que, de acordo com as mudanças nas políticas de saúde mental, que têm como foco manter o doente mental em seu contexto familiar e social, o profissional da saúde deve voltar-se para a prática exigida por essa clientela, que envolve o cuidado no seu sentido mais amplo, ou seja, ser executado de acordo com a necessidade estabelecida por eles, e não com a determinada pela equipe de saúde. Torna-se notória a necessidade de o profissional utilizar o tempo como uma ferramenta de escuta para melhorar a qualidade da assistência, já que depreendemos neste estudo que a temporalidade de cuidar de um ser esquizofrênico aviva sentimentos de angústia, provenientes de não ter com quem nem como compartilhar os anseios que Ihe causa a doença mental, limitando assim sua qualidade de vida.

\section{REFERÊNCIAS}

1. Cordeiro JCD. Manual de Psiquiatria Clinica. 2ed. Lisboa: Editora Gulbenkian; 2002.

2. Barros H. Afronta a Sanidade. Correio Brasiliense. Secretaria de Estado de Saúde. 11/01/2006. Disponível em: http://www.saude.df.gov.br/003/00301009.asp?ttCD $\mathrm{CHAVE}=30236$. Acessado em: 12/02/2009.

3. Stuart GW, Laraia MT. Enfermagem Psiquiátrica. 4ed. Rio de Janeiro: Reichmann \& Affonso Editores; 2002.

4. Pereira MAO, Pereira JRA. Transtorno mental: dificuldades enfrentadas pela família. Rev Esc Enferm USP 2003; 37(4): 92-100.
5. Koga M, Furegato AR.Convivência com a pessoa esquizofrênica: sobrecarga familiar. Ciênc Cuid Saúde 2002; 1(1):75-80

6. Mello R. A Construção do Cuidado à família e a consolidação da reforma psiquiátrica. Rev Enferm UERJ 2005; 13(3): 390-95

7. Heidegger M. Ser e Tempo. 16ed. Rio de Janeiro: Ed Universitária São Francisco; 2006.

8. Josgrilberg RS. O método fenomenológico e as ciências humanas. In: Castro DSP, Pokladek DD, Azar FP, Piccino JD, Josgrilberg RS (Org.). Fenomenologia e análise do 
existir. São Paulo: Sobraphe; 2000. p. 75-93.

9. Brasil. Ministério da Saúde. Conselho Nacional de Saúde. Resolução no 196, de 10 de outubro de 1996. Brasília; 2005.

10. Delgado JA. Aproximação à compreensão ontológica da família baseada no pensamento de Heidegger [tese]. Florianópolis (SC): 2003. Universidade Federal de Santa Catarina; 2003.

11. Andrade VCC, Mikuni PK, Melo OS, Sales CA. O estar-só e o estar-com um ente querido durante a quimioterapia. Rev Enferm UERJ 2006; 14(2): 226-231.

12. Trajano EMA. Avaliação da concepção familiar sobre a esquizofrenia. Rev. Espaço Acadêmico 2008; 85(6): 1-5.

13. Carvalho MVB, Merighi MAB. O cuidar no processo de morrer na percepção de mulheres com câncer: uma atitude fenomenologia. Rev Latino-Am Enfermagem 2005; 13(6): 951-59.

14. Colvero LA, Ide CAC, Rolim MA. Família e doença mental: a difícil convivência com a diferença. Rev Esc Enferm
USP 2004, 38(2):197-205.

15. Jorge MSB, Freitas CHA, Luz PM, Cavaleiro LMM, Costa RF. Enfermagem na atenção sistemática de saúde à família de pessoas com transtorno mental: estudo bibliográfico. Rev RENE 2008; 9(1):129-136.

16. Silva MBC, Sadigursky D. Representações sociais sobre o cuidar do doente mental no domicílio. Rev Bras Enferm 2008; 61(4): 428-34.

17. Araújo MÂM, Moreira KAP, Silveira LC, Braga VAB. A logoterapia e suas relações com os cuidados em saúde mental. Rev RENE 2008; 9(4):158-64.

18. Martins AM. Consciência de finitude, sofrimento e espiritualidade. O mundo da saúde 2007, 31(2): 174-78.

19. Souza AJ F, Matias GN, Gomes KFA, Parente ACM. A saúde mental no Programa de Saúde da Família. Rev Bras Enferm 2007; 60(4): 391-95.

20. Selli L. Dor e sofrimento na tessitura da vida. O Mundo da Saúde 2007, 31(2): 297-300. 